\title{
Generation and store of aeolian energy in form of Hydrogen using multipole aeolian generators
}

\author{
SAN MARTÍN, José Javier ${ }^{1}$, ROMERO, David ${ }^{1}$; ROMERO, Eduardo ${ }^{1}$; ZUAZUA, Jon ${ }^{1}$; APERRIBAY, Víctor ${ }^{2}$; \\ SAN MARTÍN, José Ignacio ${ }^{1}$; ARRIETA, José $M^{a}{ }^{1}$; MARTÍN, Iñaki ${ }^{1}$ \\ ${ }^{1}$ Department of Electrical Engineering \\ ${ }^{2}$ Department of Graphic Expression and Engineering Projects \\ EUITI Eibar (University of the Basque Country) \\ Av.Otaola 29, 20600 Eibar (Spain) \\ phone: 943033065, fax: 943033110, e-mail: iepsmdij@sb.ehu.es
}

\begin{abstract}
The objective of the communication is to show the possibilities for an aeolian generator when (it is) generating energy. One option is (will be) injecting the energy directly to the network and the other one is to produce hydrogen to store the energy. After that this hydrogen will be used in fuel batteries to produce electricity.

The obtained hydrogen from conventional energies has a high ecological cost by the polluting gases discharge to the atmosphere. These gases produce serious damages in our surroundings, as the greenhouse effect and acid rain are examples of this.

The hydrogen is considered a clean energy, when non-polluting energies are used to produce it. For example the renewable energies. In this case it is denominated green hydrogen. An option with promising future seems to be the production of hydrogen, with the energy generated in photovoltaic panels and aeolian generators.
\end{abstract}

Key words: Aeolian generator, Fuel cells, Hydrogen, electrolysis, renewable energies.

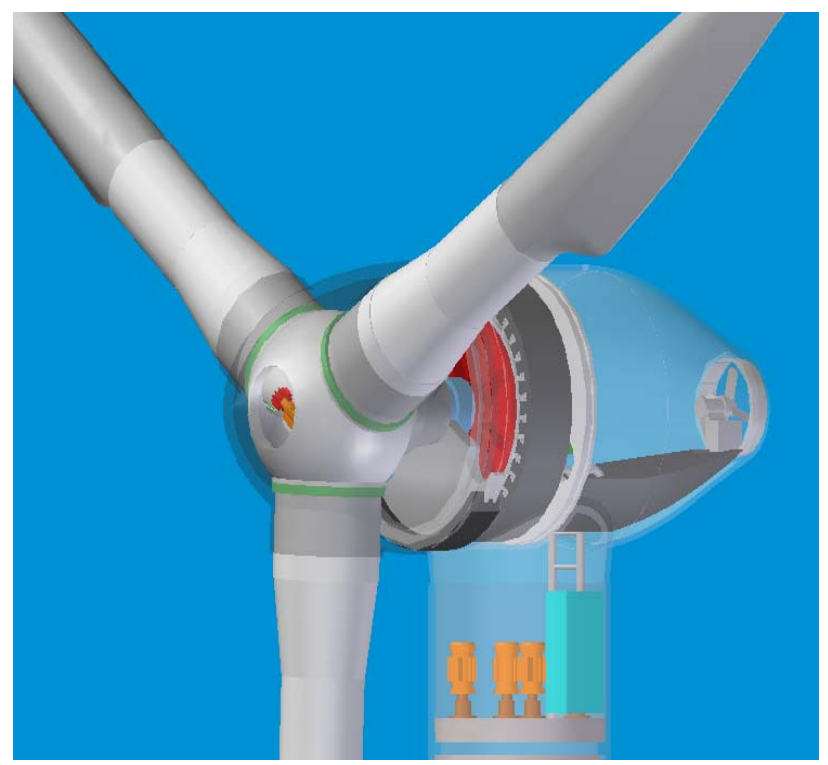

Fig. 1. Multipole Aeolian generator (gearbox without)

\section{Further Information}

\section{A) Quantification of the wind energy}

When the wind speed affects to an aeolian generator, forces take place on the shovels. These forces develop mechanical par and efforts on the mechanical elements of the aeolian generator. When the mechanical par developed by the turbine, is turning at a certain speed, produces a mechanical power that by means of the turn of the movable coil of the generator creates an exciting magnetic field that produces electrical energy.

Generally, the aeolian generators have a gearbox or converter of par, which transforms the low wind speeds into more elevated speeds. Some turbines include systems of control of the step of shovel in order to regulate the quantity of power to be transformed. The systems that do not have this control are denominated step of fixed shovels or stall.

In order to initiate the study of the wind power that hits on the shovels of the aeolian generator we will consider an infinitesimal volume of the wind tube that has a speed "v" and a thickness:

$$
L=v \cdot t
$$

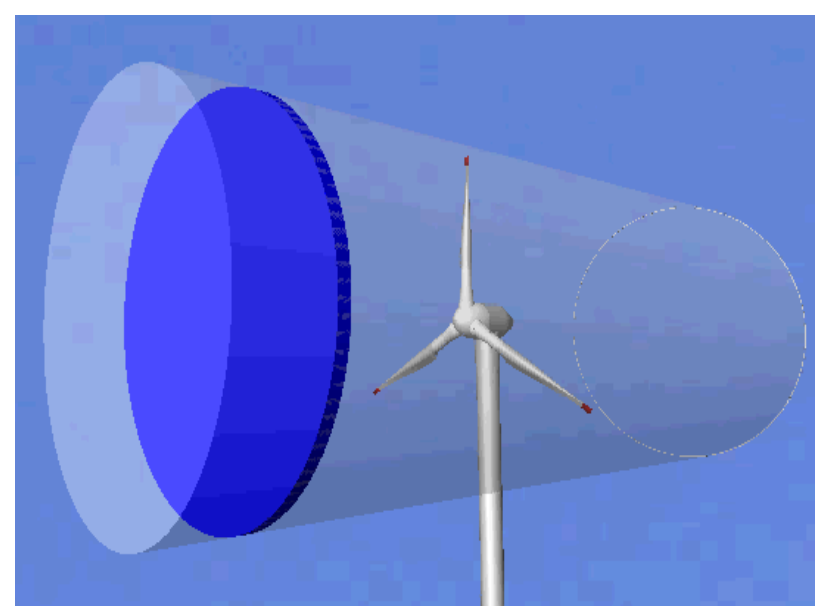

Fig. 2. Wind tube 
The mass of this infinitesimal element is:

$$
M=\rho \cdot \pi \cdot r^{2} \cdot v \cdot t
$$

The contained kinetic energy in the same one is:

$$
E_{c}=\frac{1}{2} M \cdot v^{2}=\frac{1}{2} \rho \cdot \pi \cdot r^{2} \cdot v^{3} \cdot t
$$

The power will be:

$$
P_{w}=\frac{E_{c}}{t}=\frac{1}{2} \rho \cdot \pi \cdot r^{2} \cdot v^{3}
$$

This is the power of the wind and the shovels of the Aeolian generator will absorb a portion of it.

The coefficient of power " $\mathrm{Cp}$ " indicates with what efficiency the aeolian generator turns the energy of the wind into electricity. In other words, it is the yield with which a turbine works expressing the portion of power that the rotor capture from the total amount of power the wind has.

The power that absorbs the shovels will be the power of the wind multiplied by the $\mathrm{Cp}$ coefficient.

$$
P_{\text {absorbed }}=\frac{1}{2} C_{p} \cdot \rho \cdot \pi \cdot r^{2} \cdot v^{3}
$$

When:

$$
C_{p}=\frac{P_{e}}{P_{w}}
$$

This coefficient is a non-linear function that depends of:

$$
\mathrm{C}_{\mathrm{p}}=\mathrm{f}_{\text {Non-linear }}(\mathrm{V}, \beta, \Omega, \mathrm{t})
$$

Being:

$$
\begin{aligned}
& \mathrm{V}=\text { wind speed } \\
& \beta=\text { pitch angle } \\
& \Omega=\text { rotor speed }
\end{aligned}
$$

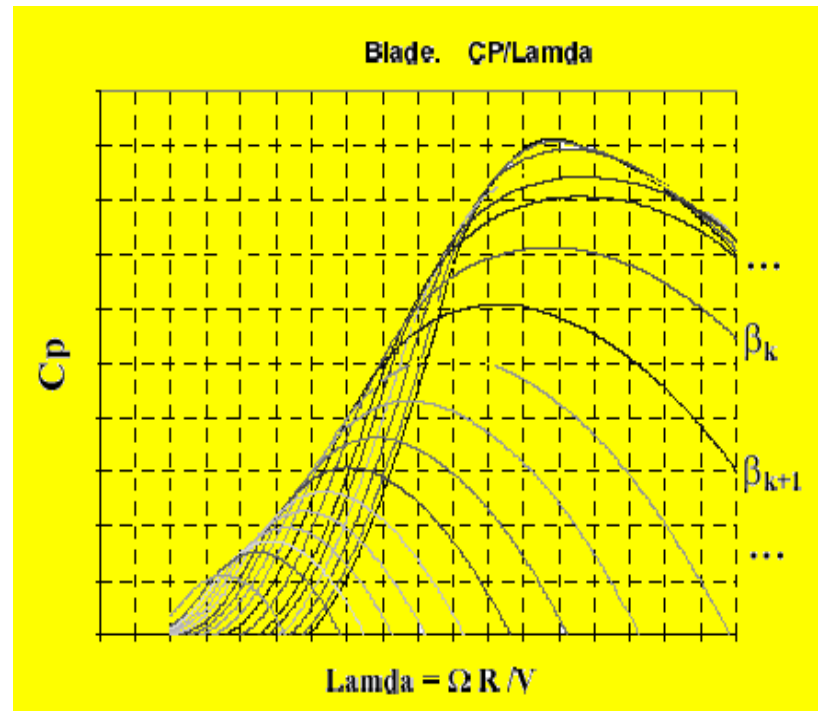

Fig. 3. Aerodynamic efficiency curves $\mathrm{Cp}$

The rest of the power not absorbed by the shovels will be:

$$
P_{w}=\left(1-C_{p}\right)
$$

In other words, whichever greater $\mathrm{Cp}$, smaller will be the residual power of the wind.

If the aeolian generator has a gearbox, the power loosed by the shovels will be reduced by the yield of the gearbox, in the opposite case this power will be the one that the rotor of the alternator absorbs.

The output power of the generator will be:

$$
P_{e}=\frac{1}{2} \rho \cdot C_{p} \cdot \pi \cdot r^{2} \cdot v^{3} \cdot \eta_{m} \cdot \eta_{g}
$$

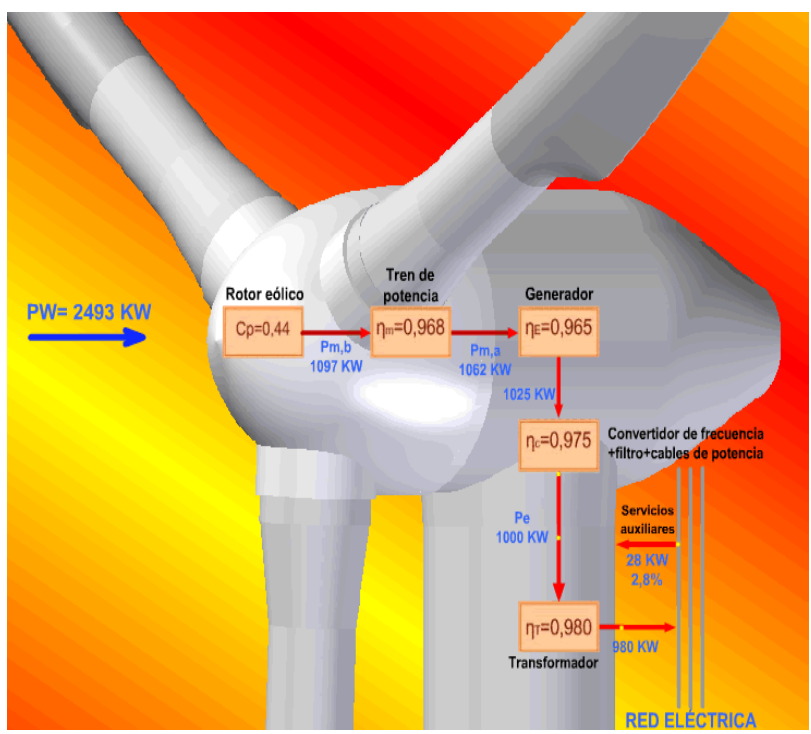

Fig. 4. Flows of power

The output power of the generator is affected by the yield of the converter. This power will be the one that enters the primary one of the transformer. The previous power is affected by the yield of the transformer too.

Summarizing, the power that we inject into the net corresponds to the graph of power flows of the figure 4 . It has the following expression:

$$
P_{n e t}=\frac{1}{2} \rho \cdot \pi \cdot r^{2} \cdot v^{3} \cdot C_{p} \cdot \eta_{m} \cdot \eta_{g} \cdot \eta_{c v} \cdot \eta_{t r}
$$

When the wind speed surpasses the nominal speed, the aeolian generator works in conditions of full load, limiting power and speed of turn. The mechanical and electrical losses remain constant and the mechanical coefficient of power is reduced to maintain the electrical power inside the allowed limits.

\section{B) Application of the multipole-generators.}

If the previous expression is observed it sees that all of the aeolian generators that use gearboxes have losses $(\eta)$. For this reason if we eliminate this mechanical component using multipole-alternators we will reduce the mechanical losses and the revolutions of the axle of the alternator of this form, the birds will be able to see the shovels better, thus reducing the risk of collision.

$$
n_{1}=\frac{60 \cdot f}{p}
$$


In these aeolian generators the speed of the axle of the shoves is equal to the speed of the rotor of the alternator.

Most of now a days aeolian generators have a transmission system that includes a gearbox to be able to use conventional generators. The tendency towards machines of greater size has been at speeds of turn of the turbine every time smaller. And therefore to relations of transmission more and more unfavourable.

An answer to this tendency forced the company M.Torres incorporate to the market the multipole synchronic generator TWT1650.

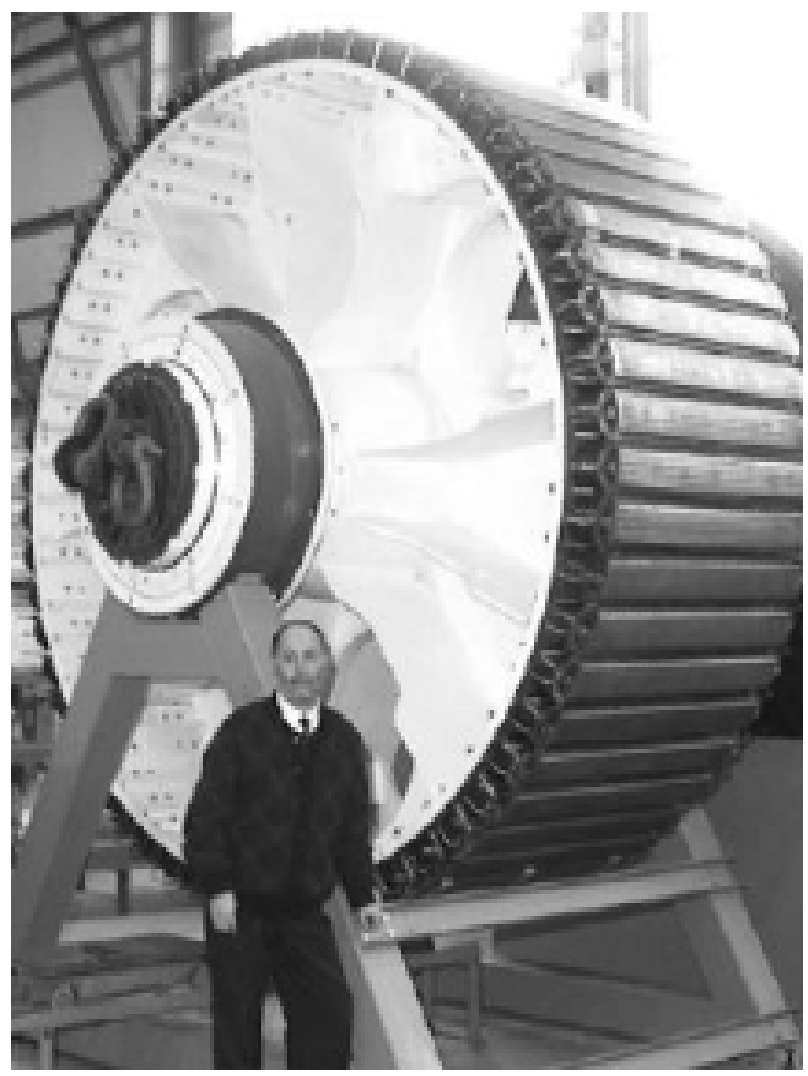

Fig. 5. Multipole-rotor (Courtesy M. Torres)

It is an aeolian generator of 64 meters of height, formed by 60 electromagnets or poles and shovels of fibre carbon of 37 meters of length that turn to 20 turns per minute. This aeolian generator is able inject electricity of better quality to the net. At the same time it is less sensitive to external failures. While a classic aeolian generator stops before micro courteous of tension, this turbine continues generating electricity. On the other hand, $30 \%$ of the errors in most of the aeolian turbines take place in the gearbox. Its oil needs to be renewed periodically.

Depending on the size, between 250 and 300 liters can be needed. All these problems disappear with the TWT (It saves up to $30 \%$ of the maintenance costs). On the other hand the aeolian generators start with a speed of $3 \mathrm{~m} / \mathrm{s}$ and they are stopped and disconnected of the electrical net when this speed reaches the $25 \mathrm{~m} / \mathrm{s}$ to avoid damages in the machine. This new turbine can continue operating with winds of up to $30 \mathrm{~m} / \mathrm{s}$.

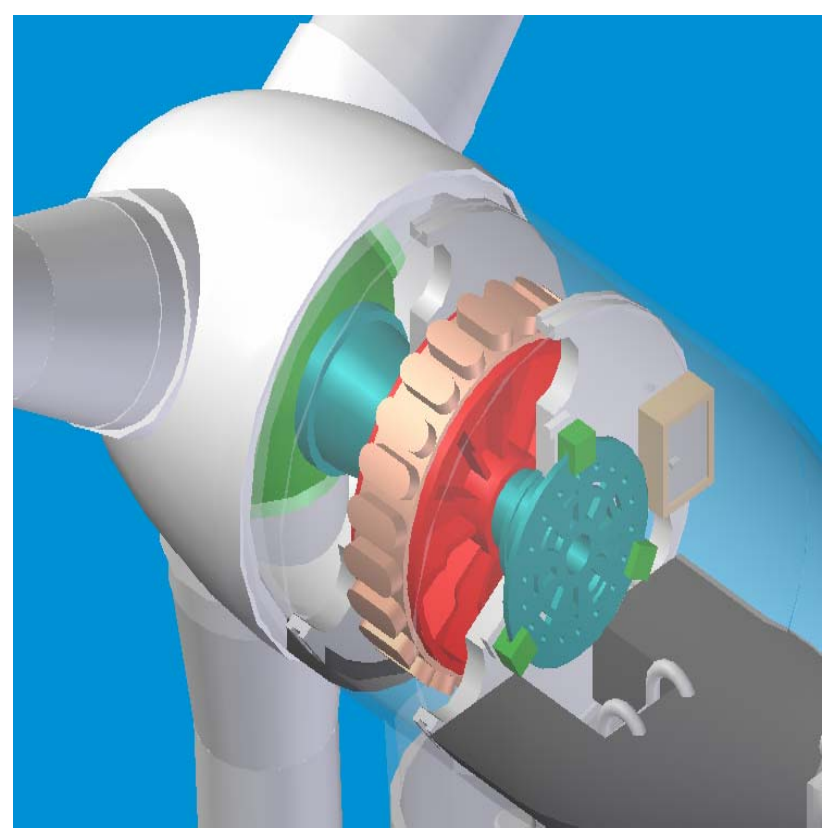

Fig. 6. Multipole aeolian generator (gearbox without)

\section{C) Storage of the wind energy}

At Off-peak hours the generated electrical energy in a windfarm may be excessive. Although the aeolian energy cannot be injected to the electrical net we can store the energy producing hydrogen by water electrolysis.

The water electrolysis is a quite trustworthy technology that allows to obtain hydrogen of great purity. The global costs of production of hydrogen will be determined by the costs of the energy that is in use, the transportation, the storage and the industrial benefits.

Chemical reaction:

Cathode: $2 \mathrm{H}_{2} \mathrm{O}+2 \mathrm{e} \rightarrow \mathrm{H}^{+}+2 \mathrm{OH}^{-}$

Anode: $\quad 2 \mathrm{OH}^{-} \rightarrow 1 / 2 \mathrm{O}_{2}+2 \mathrm{e}^{-}+\mathrm{H}_{2} \mathrm{O}$

The key factors favouring the PEM electrolyser are that it avoids the requirement to circulate a liquid electrolyte, it operates at a high current density (offering a small footprint), and it has the intrinsic ability to cope with transient variations in electrical power input (hence it has outstanding applications flexibility with respect to capturing intermittent renewable electricity supplies, such as wind and solar power.

To generate hydrogen by means of water electrolysis it is needed an electrical power in form of DC current. In our case produced by the aeolian generators. (Previously rectified).

All of these operations of generation and storage of hydrogen will be made in underground structures, located in the same wind-farm, thus reducing the visual impact. These underground structures would need to be ventilated sufficiently due to the danger derived from the storage of hydrogen in closed sites. 


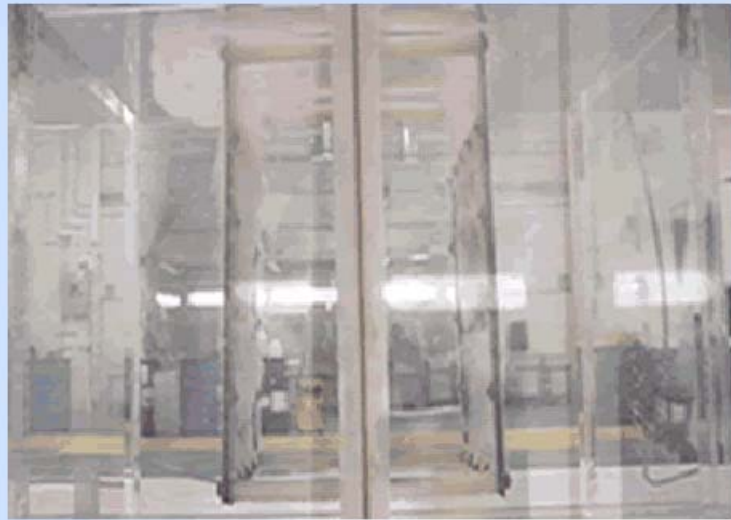

Real electrolyzer

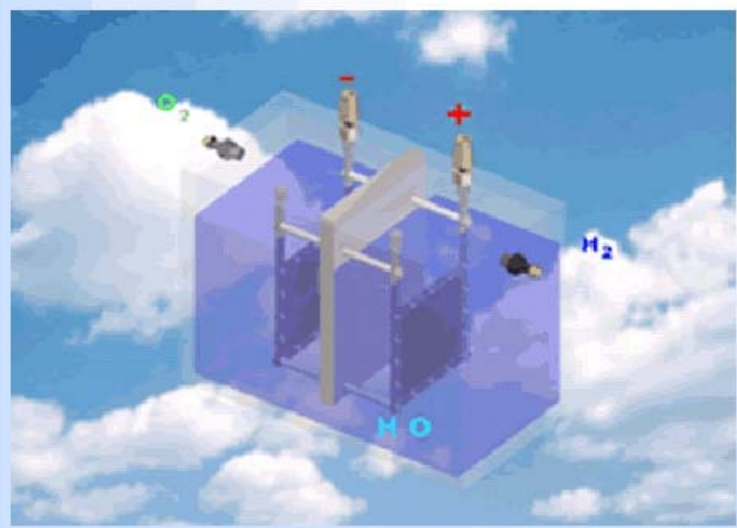

Virtual electrolyzer

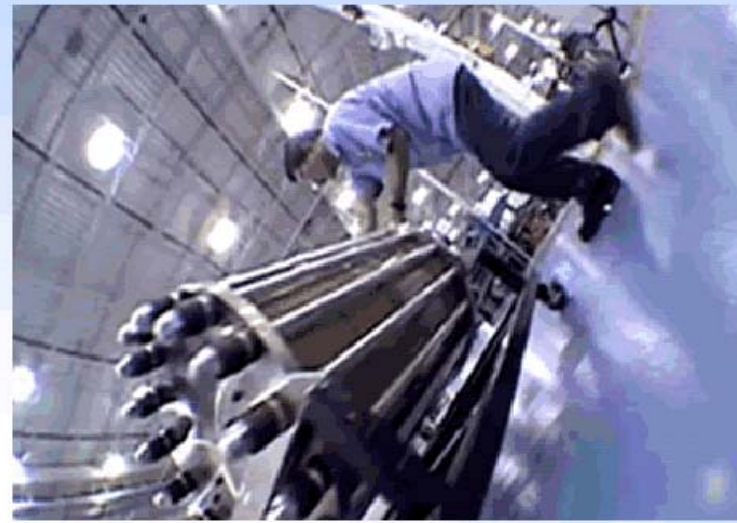

Real Fuell Cell

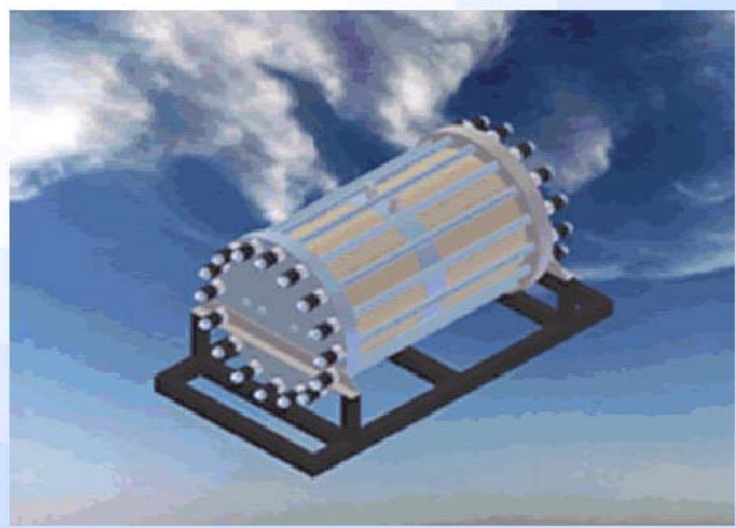

Virtual Fuell Cell

Fig. 7. Electrolyzer and Fuel Cell

Once Hydrogen is obtained, it can be stored in pressuriced deposits, cryogenic deposits $\left(-253^{\circ} \mathrm{K}\right)$, or fixed chemically to metallic hydrocarbons. The hydrogen can be transported in deposits or by gaslines (hidrogenlines). The storage supposes normally, a energy cost (around 10\%, for the compression to high pressure, and until a $30 \%$ for liquefaction).

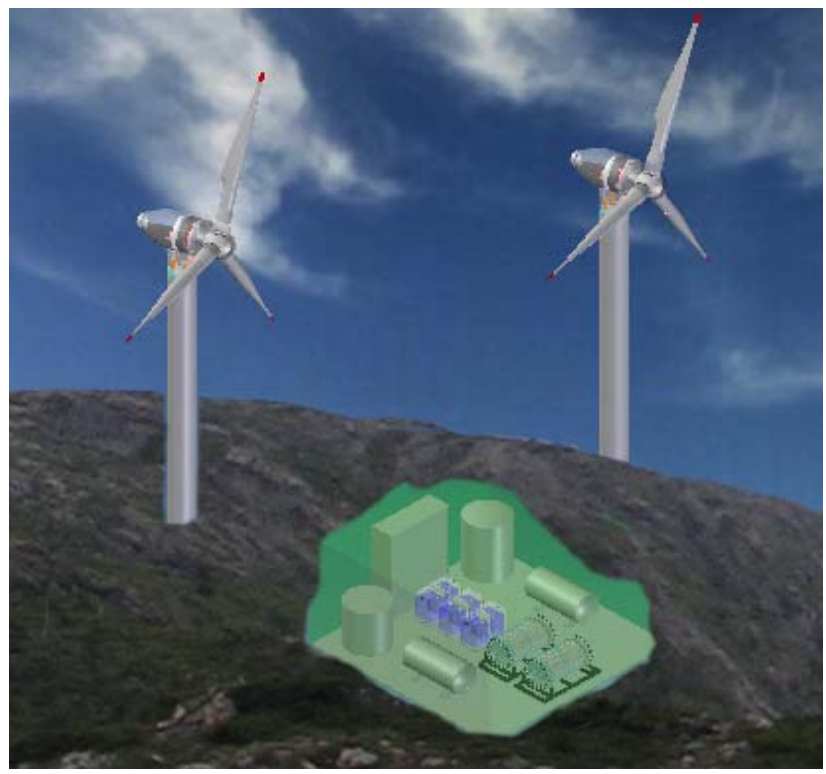

Fig. 8. Windfarm and underground installations
Stored hydrogen feed fuel cells. These fuel cells will generate current that can be injected to the electrical net on-peak power demand together with the energy generated in the wind-farm.

This solution could be an alternative to storage of electrical energy in form of potential energy by means of water pumping.

\section{Conclusions}

For the advantage of aeolian energy we will use aeolian generators of high efficiency, multipoles, without gearbox, reducing transmission losses and the noise. On the other hand we will save up to 250 litters per year of lubricating oil.

All this is translated into a $40 \%$ gain of power in comparison with a conventional aeolian generator. The shovel speeds needed are also reduced. his way, the birds will see the shovels better, thus avoiding the impact of the birds with them.

The Hydrogen generated in the wind-farm can be canalized to the distribution stations of hydrogen by means of hydrogen-lines or transported via highway in liquid form to optimize the volume. 


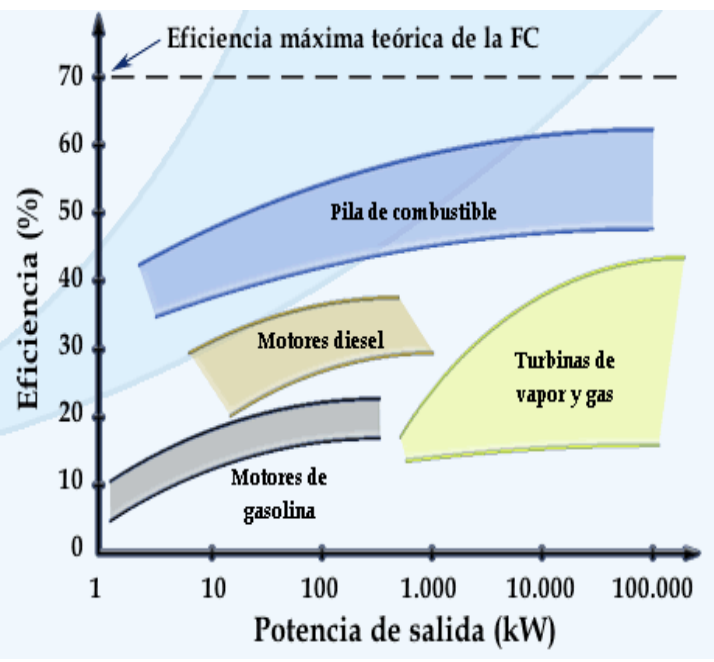

Fig. 9. Energy efficiency according to technology
The generated Hydrogen would feed the fuel cells that have an electrical yield of up to $50 \% .92 \%$ if the thermal energy is born in mind. In Figure 9, we can see the yield or efficiency of the different devices that generate electric power, fuel cells being outlined between all of them.

\section{References}

[1] A. Macdonald, M. Berry, Reseach Notes - Clean Energy for the Future, Berlin, 2003.

[2] I Encuentro Científico del Hidrógeno y las Pilas de Combustible, Madrid (2004).

[3] www. windpower.org

[4] www.ecoterra.org

[5] www.energias-renovables.com

[6] www.mtorres.es

[7] www.ballard.com

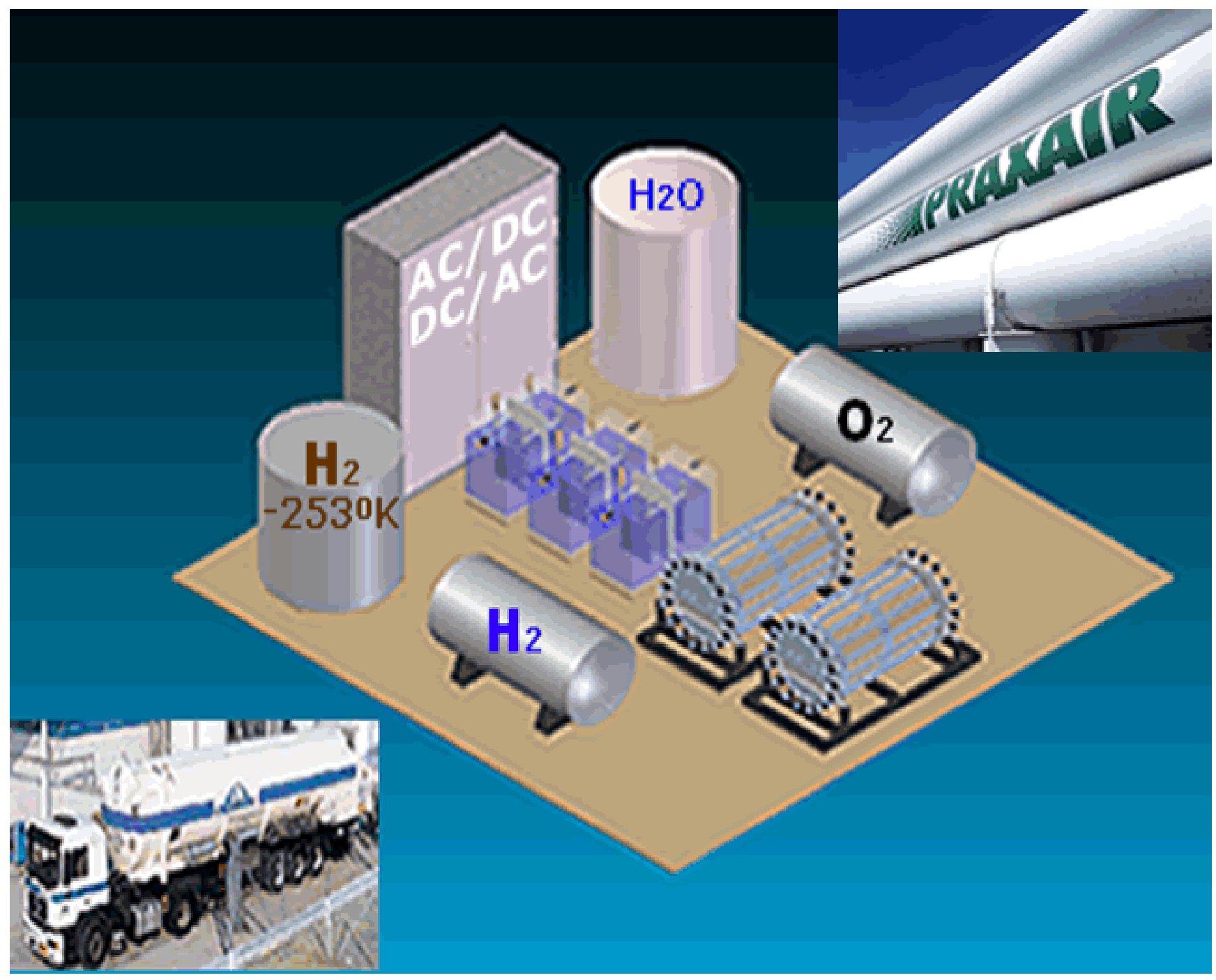

Fig. 10. Generation and distribution of the Hydrogen. (By means of Hydrogen-line or with the help of special truck) 